\title{
Research on Effects of Industrial Agglomeration on FDI in China
}

\author{
Bing Lin \\ International Economics and Trade Department, School of Economics, Shandong University of Technology, Zibo, China \\ Email: 110235359@qq.com
}

How to cite this paper: Lin, B. (2021) Research on Effects of Industrial Agglomeration on FDI in China. Open Access Library Journal, 8: e7945.

https://doi.org/10.4236/oalib.1107945

Received: September 10, 2021

Accepted: October 9, 2021

Published: October 12, 2021

Copyright $\odot 2021$ by author(s) and Open Access Library Inc.

This work is licensed under the Creative Commons Attribution International License (CC BY 4.0).

http://creativecommons.org/licenses/by/4.0/

\section{(c) (i) Open Access}

\begin{abstract}
Since the reforming and opening up in China, many manufacturing multinational corporations (MTCs) have been attracted to invest in China's eastern coastal regions. There are agglomeration characteristics of manufacturing FDI presented in the eastern region of China. The purpose of research in this paper is to study the relationship between industrial agglomeration and FDI in China. We analyze that industrial agglomeration has impacted manufacturing FDI through effects of scale economy, industrial correlation, transaction cost, and innovation. At last, relevant policies and measures for industrial agglomeration are put forward to promote the development of FDI in China.
\end{abstract}

\section{Subject Areas}

Development Economics

\section{Keywords}

Industrial Agglomeration, FDI, Agglomeration Effects

\section{Introduction}

With the deepening of economic globalization, the nature of international specialization also has been changing quietly. The international intra-product specialization in FDI of MTCs has gradually occupied a dominant position. MTCs have distributed different sections or processes of the production chains in different global areas according to the principle of comparative advantage. The location choice of international specialization or investment has been more and more concentrated on areas with comparative advantage. The conclusions in previous researches about the relationship between industrial agglomeration and FDI have two main aspects. On one hand, industrial agglomeration plays a posi- 
tive role in promoting FDI [1]. Owing to the cost comparative advantage is an important reason for a country to participate in international trade according to traditional theory. Industrial agglomeration can attract more factors agglomeration and result in a big cost gap in different regions. These form a "centripetal force" to promote more FDI in the regions having cost advantage and deepen the regions' degree of division of labor. On the other hand, the industrial agglomeration has probably a negative effect on FDI [2]. According to the new trade theory and new economic geography, industrial agglomeration not only reduces the cost through scale economy but also leads to a fierce competition resulted in the frustration of FDI, thus forming a "centrifugal force" to FDI [3]. Therefore, we will deeply analyze the impact of industrial agglomeration on FDI in this paper combined with the data of China's manufacturing industry, and explore the policies and measures on how to use industrial agglomeration to promote the effective development of FDI.

\section{Current Situation of Manufacturing Industry Agglomeration and FDI in China}

The location entropy index is more and more widely used in academic researches to explain the relationship between the degree of industrial agglomeration in a region. It is shown in formula (1):

$$
L Q_{i, j}=\frac{q_{i, j}}{\sum_{i=1}^{M} q_{i, j}} / \frac{\sum_{j=1}^{N} q_{i, j}}{\sum_{i=1}^{M} \sum_{j=1}^{N} q_{i, j}}
$$

In the formula, $L Q$ represents the location entropy index, which means the degree of industrial agglomeration. $i$ represents all regions in a country, $j$ represents all industries in a country, and $q$ represents the employment of $j$ industries in $i$ region. The location entropy index is used to measure the degree of industrial agglomeration. When the location entropy index of the region is more than 1 , it indicates that the level of industrial agglomeration in the region is higher than the national average level. The larger the index is, the higher the level of agglomeration is.

Using the location entropy, we calculate the location entropy of manufacturing industries of 31 provinces and autonomous regions in China from 2012 to 2018 , according to the relevant data in the statistical yearbooks of every province and autonomous region. Meanwhile, we also calculate the attraction degree of FDI using the employment of foreign-funded enterprises in every region as the index of development of FDI, which is shown in Graph 1.

The following conclusions can be drawn from the analysis of Graph 1:

Firstly, the eastern coastal provinces are the regions where industrial agglomeration and foreign investment are concentrated. According to the ranking of location entropy, Guangdong, Fujian, Jiangsu, Tianjin and Shanghai are the top five agglomeration regions. At the same time, Shanghai, Tianjin and Jiangsu are the top three important provinces to attract FDI enterprises. 


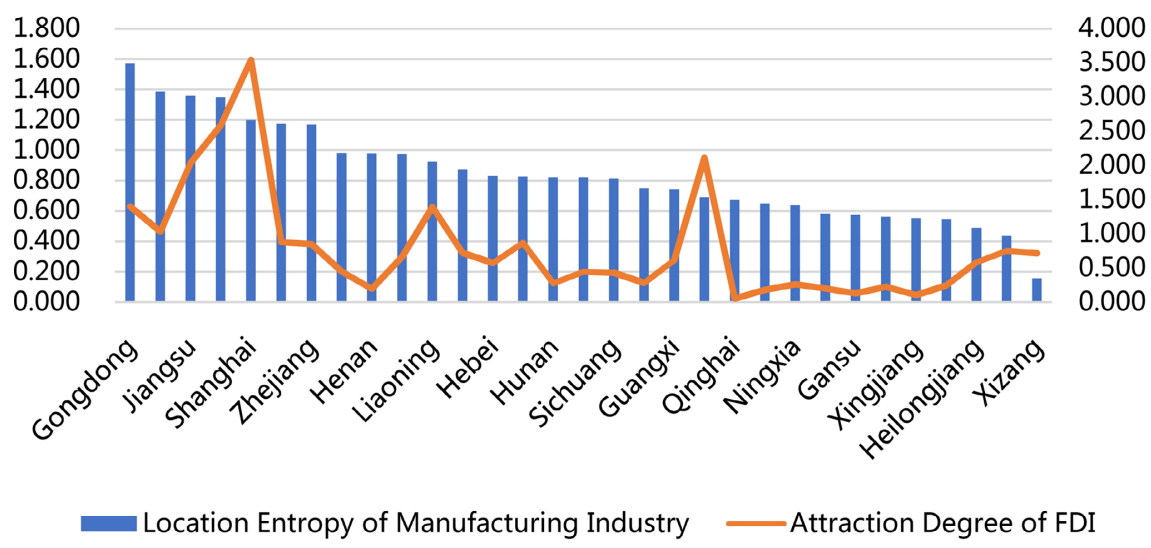

Graph 1. Location entropy of manufacturing industries and attraction degree of FDI. Sources: The statistical yearbooks of China.

Secondly, there are few regions where the degrees of industrial agglomeration and FDI are not fully coordinated. Although Shandong and Zhejiang in the eastern regions have a high degree of industrial agglomeration, 1.176 and 1.169 respectively, the level of FDI of the two provinces is less than $50 \%$ of that of Shanghai, Jiangsu and Tianjin. The industrial agglomeration level of Liaoning and Beijing is at a medium level, 0.925 and 0.690 respectively, but the attraction degree of FDI ranks $3^{\text {rd }}$ and $5^{\text {th }}$ in China respectively. It indicates that the level of regional FDI is not only positively affected by the degree of industrial agglomeration, but also affected by other factors.

Thirdly, the overall situation is that the agglomeration and foreign investment levels are relatively high in the eastern regions, and they are relatively lower in the western regions. In particular, the level of Yunnan, Ningxia, Guizhou, and Gansu Qinghai has shown a lower development state.

\section{Effects of Industrial Agglomeration on Manufacturing FDI}

\subsection{Scale Economic Effect}

There are a large number of enterprises having the same types and characteristics in industrial agglomeration regions, which form scale and comparative advantages [4]. The same enterprises can attract an abundant labor force which can be useful for the formation of a specialized market in the agglomeration regions [5]. Further, the utilization of various infrastructure natural resources can also be shared, which is more attractive to manufacturing FDI.

\subsection{Correlation Effect}

The closer relationship among enterprises in the agglomeration regions makes more affiliated enterprises enter the same regions [6]. The enterprise network in the regions will be more perfect with the continuous participation of affiliated enterprises. Due to the sharing of resources, the costs can be reduced and the competition capacity also can be enhanced. In general, this correlation increases the competitiveness of industrial clusters and is conducive to attracting FDI. 


\subsection{Cost Effect}

The scale effect and correlation effect of industrial agglomeration will greatly reduce the cost. For example, agglomeration increases the association among the enterprises. The agglomeration of upstream and downstream industries greatly reduces the information cost of "looking for customers". In addition, the geographical distance saves transportation costs and communication costs. The agglomeration of similar enterprises makes the similar demand direction more clear and the scope of enterprise customers wider, which saves publicity costs and reduces transaction risks. However, it is imperative to consider the transaction cost between the final destination of sales and the place of production If the transaction cost is higher than the cost saved by agglomeration, it will also lead to a negative effect on FDI.

\subsection{Innovation Effect}

Enterprises will pay more attention to innovation improving their competitiveness, because of the cooperative and competitive relation coexisting in the agglomeration regions. The survivors are the enterprises according to the principle of "keeping the superior and eliminate the inferior". It is urgent to improve the technological progress, management efficiency and competitiveness of enterprises. Of course, competition also has a "double-edged sword" effect. If enterprises cannot effectively use the innovation effect, they will be at risk of technology falling behind and being eliminated by the market. The attraction of FDI investment in the region will be reduced.

\section{Policy Measures}

Firstly, enterprises should combine their strength to form scale and correlation effects. Scale effect not only reduces the costs but also shares the risks. Enterprises enhance their strength through upstream and downstream industrial linkages. Driven by these effects, the positive effect of industrial agglomeration will impact FDI. Deep-seated relationships will be established through sharing resources and reducing the investment risk of FDI each other.

Secondly, governments should pay attention to the establishment of technology R \& D centers, or attract more high-tech FDI enterprises to invest in projects and regional innovation networks. When the clustered industries can only produce parts or intermediate products for product manufacturing, the distance between the final destination of sales and the place of production will also become an important factor to restrain FDI. Forming a technological innovation atmosphere will also drive more enterprises to make effective use of innovation effects and enhance competitiveness.

At last, regional governments should make rational use of their comparative advantages in resources and should not over-exploit resources. It is important to make effective use of regional factor endowment and rational allocation of resources. In the process of undertaking industrial transfer and promoting indus- 
trial upgrading, local governments should fully consider natural resources, factor endowment, regional specialization level and other factors. It is necessary to realize the effective allocation of resources, guide FDI projects driving the economic development of the region according to their own advantages, and promote the exertion and utilization of the positive effect of industrial agglomeration.

\section{Conflicts of Interest}

The author declares no conflicts of interest.

\section{References}

[1] Zheng, X.Y. (2019) The Impact of High-tech Industrial Agglomeration on Foreign Direct Investment-A Case Study of Shanghai. China Market, No. 29, 1-4+8.

[2] Sun, P.Y., Han, S. and Jin, S.J. (2012) Analysis of the Impact of Industrial Agglomeration on Foreign Direct Investment-A Comparative Study Based on Service Industry and Manufacturing Industry. Quantitative Economy and Technical Economy Research, 29, 40-57.

[3] Krugman, P. (1990) Increasing Returns and Economic Geography. Working Paper No. 3275. https://doi.org/10.3386/w3275

[4] Weber, A. (1909) The Theory of The Location of Industries. The University of Chicago Press, Chicago \& London.

[5] Liu, D.P. (2020) Measurement, Significance Test and Evolution Trend of Manufacturing Agglomeration in Anhui Province-Based on 29 Double-Digit Manufacturing Industry Data in Anhui Province. Journal of Changchun University, 30, 24-30.

[6] Liu, X.Y. (2020) Does Industrial Agglomeration Affect the Accuracy of Analysts' Earnings Forecasts? American Journal of Industrial and Business Management, 10, 900-914. https://doi.org/10.4236/ajibm.2020.105060 